\title{
The Economic Burden of End-Organ Damage Among Medicaid Patients with Sickle Cell Disease in the United States: A Population-Based Longitudinal Claims Study
}

\author{
Andrew Campbell, MD; Ze Cong, PhD; Irene Agodoa, MD; Xue Song, PhD; \\ Diane J. Martinez, DrPH, MPH; Danae Black; Carolyn R. Lew, PhD; Helen Varker; \\ Chris Chan, MPH; and Sophie Lanzkron, MD, MHS
}

\begin{abstract}
BACKGROUND: The management of sickle cell disease (SCD), an inherited, chronic, and multifaceted condition, is associated with considerable health care resource utilization (HRU) and costs, especially for Medicaid. Anemia affects most patients with SCD and correlates with end-organ damage (EOD), such as stroke, chronic kidney disease (CKD), end-stage renal disease (ESRD), and pulmonary hypertension (PH). Limited research has been conducted to quantify the economic burden of EOD among patients with SCD.
\end{abstract}

OBJECTIVE: To estimate the effect of EOD on HRU and direct costs and productivity loss incurred by patients with SCD on Medicaid.

METHODS: Patients with $\geq 3$ nondiagnostic SCD ICD-9-CM/ICD-10-CM codes in $\leq 5$ years (January 1, 2013-December 31, 2017) were identified in the MarketScan Medicaid claims database. The earliest SCD diagnosis date was the index date. Continuous enrollment at least 3 months before and 1 month after the index date were required. Patients' post-index periods were divided into 3-month intervals (referred to as "intervals"). History of stroke, CKD, ESRD, and PH were identified in patients' claims histories from January 1, 2008. Intervals within 1 year and more than 1 year after an acute stroke event were also defined. All-cause HRU, direct costs, and productivity losses were summed across intervals and stratified by EOD type. Multivariate regression models were used to estimate the effect of stroke, CKD, ESRD, and PH on annual total cost, inpatient days, and number of emergency department visits by controlling for patients' demographic characteristics and other SCD complications.

RESULTS: In total, 10,784 Medicaid patients with SCD (average age: 18.5 years; female: $54.5 \%$ ) contributed to 152,455 intervals. Approximately $12 \%$ of the intervals had EOD. Patients with EOD had higher all-cause health care costs and more inpatient days, emergency department visits, outpatient visits, laboratory tests, and outpatient pharmacy claims than patients without EOD. After controlling for patient characteristics, among Medicaid patients with SCD annual costs within 1 year after stroke were 4.68-fold versus patients with no EOD (more than 1 year after stroke: 2.08fold; CKD: 2.19-fold; ESRD: 3.40-fold; PH: 2.32-fold). Adjusted mean annual costs for adult patients with SCD on Medicaid were $\$ 285,816$ and $\$ 127,393$ within 1 year and more than 1 year after stroke and $\$ 135,493, \$ 209,172$, and $\$ 148,174$ for CKD, ESRD, and PH, respectively. Patients with multiple SCD complications had even higher costs. The mean annual time patients with SCD spent receiving health care services ranged from 56 to 62 days for those with EOD versus 21 to 25 days among those without EOD, which created additional economic burden.

CONCLUSIONS: When Medicaid patients with SCD experience EOD, the economic burden is significantly increased through direct costs to the health care system and indirect costs from productivity loss to society.
SCD management strategies that potentially reduce the risk of EOD offer clinical and economic value to patients and society.

\section{J Manag Care Spec Pharm. 2020;26(9):1121-29}

Copyright $\odot 2020$, Academy of Managed Care Pharmacy. All rights reserved.

\section{What is already known about this subject}

The use of medical resources among patients with sickle cell disease (SCD) contributes to high medical costs.

Anemia and hemolysis lead to end-organ damage (EOD; i.e. stroke, chronic kidney disease, end-stage renal disease, and pulmonary hypertension) among patients with SCD.

\section{What this study adds}

EOD further increases the economic burden of SCD, with health care costs 2-5 times higher among patients with SCD with EOD compared with those without EOD.

Patients with multiple SCD complications had even higher costs, with an adjusted mean annual cost of $\$ 417,614$ for adult patients with SCD, end-stage renal disease, and other SCD complications, such as avascular necrosis.

Patients with SCD with EOD spent more than double the amount of productive time on health care compared with patients without EOD, limiting career opportunities and income potential.

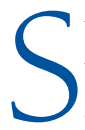
ickle cell disease (SCD) is a genetic disorder resulting in elongated, sickle-shaped red blood cells that affects approximately 100,000 Americans and occurs most frequently in people with African heritage..$^{1-3}$ The chronic nature of SCD and its associated complications contribute to patients' high rate of health care utilization and costs, ${ }^{4,5}$ with an estimated lifetime cost for a patient with a 50-year life expectancy of $\$ 8,747,908 .^{5,6}$ According to the Healthcare Cost and Utilization Project's 2019 report, the aggregate of inpatient stays for SCD from 2000 to 2016 cost more than $\$ 800$ million, with approximately $50 \%$ of patients having Medicaid as the expected payer. ${ }^{3}$ 
Chronic complications of SCD can affect nearly every organ, and the occurrence of new complications increases with age. ${ }^{2}$ Anemia and hemolysis contribute to progressive organ damage of the brain, kidneys, and cardiovascular system and are associated with a number of conditions, including neurocognitive dysfunction, silent cerebral infarction, stroke, renal dysfunction, pulmonary hypertension, and mortality. ${ }^{7}$ End-organ damage (EOD; i.e., stroke, chronic kidney disease [CKD], end-stage renal disease [ESRD], and pulmonary hypertension $[\mathrm{PH}]$ ) may impose a significant burden on the health system and economy, ${ }^{2,8,9}$

The indirect costs for patients with SCD may also be high, with health complications increasing the number of days children are absent from school and adults are absent from work. ${ }^{8}$ Repeated and lengthy hospital stays can impede full employment status for adults, with an average length of SCDrelated inpatient hospitalization of 5 days, and $39.4 \%$ of adults aged 18-34 years experiencing at least 1 all-cause readmission within 30 days of discharge. ${ }^{3}$ Among patients covered by Medicaid, those aged 18-30 years had 3 times as many emergency department (ED) visits and inpatient admissions than those younger than 18 years. ${ }^{4}$ Additionally, $73 \%$ of patients reported being unable to fully perform their duties (i.e., presenteeism) for more than 100 working days each year. ${ }^{10}$ Many patients were unable to work (43.8\%), and only $31 \%$ were employed or self-employed. ${ }^{10}$ Patients with SCD, particularly those who are economically disadvantaged, are less engaged with support services, make more ED visits, and have lengthier inpatient hospitalizations than patients without SCD. ${ }^{3}$

Although existing research describes EOD in patients with SCD, ${ }^{11-14}$ the economic burden of EOD in these patients has not been assessed. Thus, the objective of this study was to determine the effect of EOD on health care resource utilization and direct costs, as well as productivity loss, among Medicaid patients with SCD.

\section{Methods}

\section{Data Source and Patient Selection}

The IBM MarketScan Multi-State Medicaid Database was used for this study. The database includes health care coverage eligibility and service use of individuals enrolled in state Medicaid programs for more than 10 geographically dispersed states and/or Medicaid managed care programs. Patients were selected if they had at least 3 inpatient or outpatient claims on different days containing a diagnosis of SCD (see International Classification of Diseases, Ninth/Tenth Revision, Clinical Modification [ICD-9-CM or ICD-10-CM] codes in the Appendix, available in online article) between January 1, 2013, and December 31, 2017. Patients dually enrolled in Medicaid and Medicare were excluded from the sample. The $\geq 3$ encounters requirement to define SCD in administrative data ensured accurate case identification. ${ }^{15}$ The earliest SCD diagnosis was

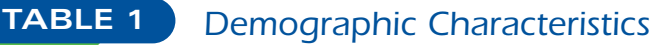

\begin{tabular}{l|r}
\hline & All Intervals (N= 152,455) \\
\hline Age, years, mean (SD) & $18.5(13.6)$ \\
\hline Male, $\mathrm{n}(\%)$ & $69,286(45.4)$ \\
\hline Urban population density, $\mathrm{n}(\%)$ & $128,714(84.4)$ \\
\hline Race, $\mathrm{n}(\%)$ & $111,839(73.4)$ \\
\hline Black & $35,890(23.5)$ \\
\hline Unknown & $2,506 \quad(1.6)$ \\
\hline White & $1,459(1.0)$ \\
\hline Hispanic & $761 \quad(0.5)$ \\
\hline Other & \\
\hline SD standard deviation. &
\end{tabular}

considered the index date. All patients were required to have at least 3 months of enrollment before and 1 month of enrollment after the index date.

\section{Study Design}

A longitudinal panel dataset analysis was conducted in which each patient's post-index period was divided into a series of 3-month intervals, with each interval considered 1 unit of observation. Use of 3-month intervals instead of annual intervals improved the precision of estimates. If the last interval was incomplete but $\geq 30$ days, the total costs were standardized as per patient per month (PPPM). Incomplete intervals of $<30$ days were likely at end of life, and costs during this short time were not generalizable; therefore, total costs during these intervals were reported without standardizing to PPPM.

\section{End-Organ Damage}

Medicaid claims with stroke, CKD, ESRD, and PH diagnoses or procedures were considered. For each 3-month interval, each patient's entire available claim history (starting from January 1 , 2008) was queried for CKD, ESRD, or PH. CKD included stages 1-4 of disease without ESRD, dialysis, and kidney transplant. ESRD was defined as a diagnosis of ESRD, CKD stage 5, or CKD of any stage with dialysis or kidney transplant. Intervals were also categorized as being within 1 year or more than 1 year after an acute stroke hospitalization.

\section{All-Cause Health Care Utilization and Costs}

Health care utilization included total number of hospitalizations, number of days spent hospitalized, physician office visits, ED visits, laboratory tests, other outpatient services, and outpatient pharmacy claims. All-cause health care cost components included inpatient; outpatient (physician office visit, ED visits, laboratory tests, and other outpatient services); and outpatient pharmacy services. All costs were inflated and adjusted to U.S. 2018 dollars. 
The Economic Burden of End-Organ Damage Among Medicaid Patients with Sickle Cell Disease in the United States: A Population-Based Longitudinal Claims Study

TABLE 2 All-Cause Health Care Utilization` Among Patients with SCD with or Without EOD (PPPM)

\begin{tabular}{|c|c|c|c|c|c|c|c|}
\hline & $\begin{array}{c}\text { No EOD } \\
(\mathrm{n}=134,444)\end{array}$ & $\begin{array}{l}\text { With EOD } \\
(n=18,011)\end{array}$ & $\begin{array}{c}\leq 1 \text { Year After } \\
\text { Acute Stroke } \\
(\mathrm{n}=575)\end{array}$ & $\begin{array}{c}\text { >1 Year After } \\
\text { Acute Stroke } \\
(\mathrm{n}=2,104)\end{array}$ & $\begin{array}{c}\mathrm{CKD}^{\mathrm{d}} \\
(\mathrm{n}=3,980)\end{array}$ & $\begin{array}{c}\text { ESRD }^{\mathrm{e}} \\
(\mathrm{n}=1,894)\end{array}$ & $\begin{array}{c}\text { PH } \\
(n=12,141)\end{array}$ \\
\hline ge, years, mean $(\mathrm{SD})$ & $16.9(12.7)$ & $29.7(14.8)$ & $25.8(16.7)$ & $24.5(16.4)$ & $35.6(16.4)$ & $38.4(13.7)$ & $29.5(13.5)$ \\
\hline Inpatient hospitalization, n (\%) & $26,412(19.6)$ & $8,063(44.8)$ & $319(55.5)$ & $619(29.4)$ & $1,632(41.0)$ & $1,010(53.3)$ & $5,872(48.4)$ \\
\hline $\begin{array}{l}\text { Number of inpatient hospitalizatic } \\
\text { PPPM, mean (SD) }\end{array}$ & $0.1 \quad(0.3)$ & $0.3 \quad(0.5)$ & $0.4 \quad(0.5)$ & $0.2 \quad(0.4)$ & $0.3 \quad(0.5)$ & $0.4 \quad(0.6)$ & $0.4 \quad(0.5)$ \\
\hline $\begin{array}{l}\text { Number of day } \\
\text { hospitalization }\end{array}$ & $0.4 \quad(1.5)$ & $(3.5)$ & $(4.4)$ & $1.1 \quad(3.0)$ & $1.6 \quad(3.3)$ & $2.5 \quad(4.3)$ & $2.1 \quad(3.6)$ \\
\hline Outpatient services used, n (\%) & $114,376(85.1)$ & $16,593(92.1)$ & $558(97.0)$ & $1,978(94.0)$ & $3,662(92.0)$ & $1,772(93.6)$ & $11,134(91.7)$ \\
\hline hysicia & $93,782(69.8)$ & $14,133(78.5)$ & $479(83.3)$ & $1,711(81.3)$ & $3,124(78.5)$ & $1,478(78.0)$ & $9,495(78.2)$ \\
\hline $\begin{array}{l}\text { Numbe } \\
\text { mean }\end{array}$ & $0.8 \quad(0.9)$ & $1.2 \quad(1.4)$ & $1.3 \quad(1.3)$ & $1.2 \quad(1.2)$ & $1.2 \quad(1.3)$ & $1.2(1.7)$ & $1.2 \quad(1.6)$ \\
\hline (\%) & $43,994(32.7)$ & $7,947(44.1)$ & $234(40.7)$ & $744(35.4)$ & $1,731 \quad(43.5)$ & $941(49.7)$ & $5,552(45.7)$ \\
\hline Number of ED visits, PPPM, mean (SD) & $0.3 \quad(0.7)$ & $0.6 \quad(1.6)$ & $0.5 \quad(1.2)$ & $0.5 \quad(1.4)$ & $0.6 \quad(1.3)$ & $0.9 \quad(2.1)$ & $0.6 \quad(1.6)$ \\
\hline Lab tests, $\mathbf{n}(\%)$ & $84,043(62.5)$ & $13,590(75.5)$ & $467(81.2)$ & $1,758(83.6)$ & $2,997(75.3)$ & $1,482(78.2)$ & $9,085(74.8)$ \\
\hline Number of lab te & $2.5 \quad(4.2)$ & $4.8 \quad(6.3)$ & $7.0 \quad(7.5)$ & $7.9 \quad(7.9)$ & $4.5 \quad(5.8)$ & $6.2 \quad(7.7)$ & $4.3 \quad(6.0)$ \\
\hline Other outpatient services, $\mathbf{n}(\%)$ & $98,104(73.0)$ & $15,196(84.4)$ & $541(94.1)$ & $1,872(89.0)$ & $3,349(84.1)$ & $1,654(87.3)$ & $10,150(83.6)$ \\
\hline $\begin{array}{l}\text { Number of other outpatient services, } \\
\text { PPPM, mean (SD) }\end{array}$ & $1.4 \quad(3.3)$ & $3.2 \quad(5.4)$ & $4.8 \quad(6.3)$ & $3.8 \quad(5.7)$ & $3.9 \quad(6.5)$ & $4.9 \quad(6.4)$ & $3.1 \quad(5.2)$ \\
\hline Outpatient pharmacy claims, n (\%) & $106,141(78.9)$ & $16,076(89.3)$ & $517(89.9)$ & $1,869(88.8)$ & $3,560(89.4)$ & $1,731 \quad(91.4)$ & $10,835(89.2)$ \\
\hline $\begin{array}{l}\text { Number of outpatient pharmacy claims, } \\
\text { PPPM, mean (SD) }\end{array}$ & $2.2 \quad(2.7)$ & $4.5 \quad(4.7)$ & $4.2 \quad(4.4)$ & $4.5 \quad(5.7)$ & $5.0 \quad(5.2)$ & $6.4 \quad(6.3)$ & $4.5 \quad(4.5)$ \\
\hline \multicolumn{8}{|c|}{ 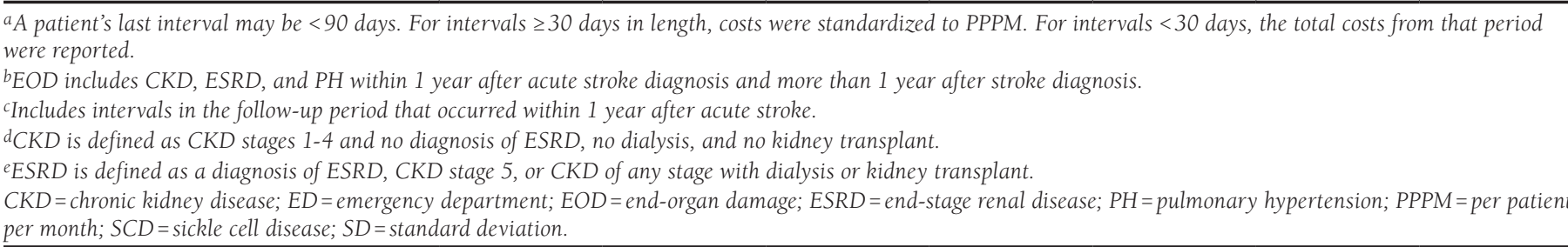 } \\
\hline
\end{tabular}

\section{Productivity Loss}

There is very limited availability of productivity loss data to quantify the extent of indirect costs associated with EOD in SCD. Therefore, to quantify the time spent receiving health care (or potential "work loss" for patients or their caregivers) based on health care resource utilization, a specified number of hours were assigned based on the literature and expert opinion for each health care service, ${ }^{16,17}$ which served as a proxy for the number of hours lost (inpatient hospitalization: 8 hours per day; physician office visit: 2 hours; other outpatient services: 2 or 4 hours for stroke or ESRD; ED visit: 5 hours ${ }^{16}$; laboratory test: 1 or 2 hours for onsite or offsite laboratory; outpatient pharmacy claims: 1 hour). The estimation of 4 hours per "other outpatient visit" was specifically applied to patients with acute stroke and/or ESRD, owing to the longer duration of care associated with these 2 conditions. The number of hours lost per health care setting were summed.

\section{Statistical Analysis}

Descriptive statistics for all outcomes and covariates were reported for each interval. Continuous variables were summarized by providing the number of observations, the mean, and standard deviations (SD). Categorical variables were presented in frequency tables. Cost and health care utilization outcomes were summed across 3-month intervals and reported for the overall study population and separately for patients with EOD versus no EOD, including subgroups of any EOD complications, within 1 year after acute stroke and more than 1 year after an acute stroke, CKD, ESRD, and PH.

Multivariate regression models were used to estimate the effect of EOD versus no EOD (reference group) on cost, inpatient days, and number of ED visits. Key independent variables were within 1 year after acute stroke and more than 1 year after acute stroke, CKD, ESRD, and PH. The other covariates adjusted in the models were age $(<6,6-11,12-17,18-30,31-44$, 45-54, 55-64, and 65+ years); gender; population density (rural vs. urban); and other SCD complications (avascular necrosis, gallstones, cholelithiasis, cholecystitis, leg ulcers, osteomyelitis, priapism, splenomegaly, splenic sequestration, and hypersplenism).

Costs were estimated using a generalized linear model, whereas number of inpatient days and number of ED visits were estimated using negative binomial models. Because each 
The Economic Burden of End-Organ Damage Among Medicaid Patients with Sickle Cell Disease in the United States: A Population-Based Longitudinal Claims Study

TABLE 3 Multivariate Regression for Medicaid Patients with SCD: All-Cause Costs, Inpatient Days, and ED Visits

\begin{tabular}{|c|c|c|c|c|c|c|}
\hline & Cost Ratio & $95 \%$ CI & $\begin{array}{c}\text { Inpatient Days } \\
\text { Ratio }\end{array}$ & $95 \% \mathrm{CI}$ & ED Visits Ratio & $95 \% \mathrm{CI}$ \\
\hline \multicolumn{7}{|l|}{ End-organ damage } \\
\hline No end-organ damage & 1.00 & - & 1.00 & - & 1.00 & - \\
\hline$\leq 1$ year after acute stroke & $4.68^{\mathrm{a}}$ & $(3.70-5.92)$ & $3.69^{\mathrm{a}}$ & $(2.94-4.63)$ & $1.68^{\mathrm{b}}$ & $(1.12-2.51)$ \\
\hline$>1$ year after acute stroke & $2.08^{\mathrm{a}}$ & $(1.77-2.44)$ & $1.74^{\mathrm{c}}$ & $(1.31-2.31)$ & $1.82^{\mathrm{b}}$ & $(1.08-3.07)$ \\
\hline CKD & $2.19^{a}$ & $(1.82-2.64)$ & $2.16^{\mathrm{a}}$ & $(1.81-2.57)$ & $1.64^{\mathrm{c}}$ & $(1.27-2.11)$ \\
\hline ESRD & $3.40^{\mathrm{a}}$ & $(2.58-4.48)$ & $3.16^{\mathrm{a}}$ & $(2.51-3.97)$ & $2.25^{c}$ & $(1.40-3.61)$ \\
\hline $\mathrm{PH}$ & $2.32^{a}$ & $(2.08-2.6)$ & $2.84^{\mathrm{a}}$ & $(2.56-3.15)$ & $1.56^{\mathrm{a}}$ & $(1.29-1.87)$ \\
\hline \multicolumn{7}{|l|}{ Age group, years } \\
\hline$<6$ & $0.40^{\mathrm{a}}$ & $(0.35-0.44)$ & $0.23^{a}$ & $(0.21-0.26)$ & $0.30^{\mathrm{a}}$ & $(0.28-0.33)$ \\
\hline $6-11$ & $0.40^{\mathrm{a}}$ & $(0.36-0.44)$ & $0.24^{\mathrm{a}}$ & $(0.22-0.26)$ & $0.23^{a}$ & $(0.22-0.25)$ \\
\hline $12-17$ & $0.55^{\mathrm{a}}$ & $(0.50-0.60)$ & $0.40^{\mathrm{a}}$ & $(0.36-0.44)$ & $0.25^{\mathrm{a}}$ & $(0.23-0.27)$ \\
\hline $18-30$ & 1.00 & - & 1.00 & - & 1.00 & - \\
\hline $31-44$ & $0.87^{\mathrm{b}}$ & $(0.77-0.99)$ & $0.81^{\mathrm{c}}$ & $(0.73-0.90)$ & 0.96 & $(0.84-1.09)$ \\
\hline $45-54$ & $0.60^{\mathrm{a}}$ & $(0.51-0.70)$ & $0.58^{\mathrm{a}}$ & $(0.49-0.69)$ & $0.68^{\mathrm{c}}$ & $(0.52-0.89)$ \\
\hline $55-64$ & $0.46^{\mathrm{a}}$ & $(0.36-0.58)$ & $0.39^{\mathrm{a}}$ & $(0.32-0.49)$ & $0.39^{a}$ & $(0.30-0.50)$ \\
\hline $65+$ & $0.32^{\mathrm{a}}$ & $(0.21-0.49)$ & $0.18^{\mathrm{a}}$ & $(0.12-0.26)$ & $0.24^{\mathrm{a}}$ & $(0.15-0.38)$ \\
\hline \multicolumn{7}{|l|}{ Gender } \\
\hline Female (vs. male) & 1.06 & $(0.99-1.14)$ & $1.14^{\mathrm{c}}$ & $(1.04-1.26)$ & 1.08 & $(0.94-1.23)$ \\
\hline \multicolumn{7}{|l|}{ Population density } \\
\hline Rural (vs. urban) & 1.00 & $(0.92-1.10)$ & 0.88 & $(0.77-1.00)$ & 1.04 & $(0.90-1.21)$ \\
\hline \multicolumn{7}{|l|}{ Other SCD complications } \\
\hline Avascular necrosis & $2.10^{\mathrm{a}}$ & $(1.89-2.32)$ & $2.41^{\mathrm{a}}$ & $(2.18-2.66)$ & $1.63^{\mathrm{a}}$ & $(1.44-1.84)$ \\
\hline Gallstones, cholelithiasis, cholecystitis & $2.06^{\mathrm{a}}$ & $(1.81-2.35)$ & $1.50^{\mathrm{a}}$ & $(1.25-1.79)$ & $1.35^{\mathrm{c}}$ & $(1.15-1.59)$ \\
\hline Leg ulcers & $1.60^{\mathrm{b}}$ & $(1.21-2.10)$ & $1.54 \mathrm{~b}$ & $(1.15-2.05)$ & 0.84 & $(0.63-1.13)$ \\
\hline Osteomyelitis & $1.84^{\mathrm{a}}$ & $(1.47-2.30)$ & $2.26^{\mathrm{a}}$ & $(1.75-2.91)$ & $1.41^{\mathrm{b}}$ & $(1.02-1.95)$ \\
\hline Priapism & $1.65^{\mathrm{a}}$ & $(1.38-1.97)$ & $1.89^{a}$ & $(1.52-2.36)$ & $2.02^{\mathrm{c}}$ & $(1.40-2.92)$ \\
\hline \multicolumn{7}{|c|}{$\begin{array}{l}a P<0.0001 . \\
b P<0.05 . \\
{ }^{a} P<0.01 . \\
C I=\text { confidence interval; } C K D=\text { chronic kidney disease; } E D=\text { emergency department; ESRD=end-stage renal disease; } P H=\text { pulmonary hypertension; } S C D=\text { sickle cell disease. }\end{array}$} \\
\hline
\end{tabular}

patient could contribute multiple observations, generalized estimating equations were also used to account for positive correlation over time among patients. Regression-adjusted annual costs, number of inpatient days, and number of ED visits were estimated separately for adult patients with SCD and different types of EOD.

\section{Results}

\section{Demographic and Clinical Characteristics}

A total of 10,784 Medicaid patients with SCD contributed 152,455 intervals. Most patients were female (54.5\%) with a mean (SD) age of 18.5 (13.6) years at the interval start. About $3 \%$ of intervals were $<30$ days, and $4 \%$ were between 30 and 89 days. The majority of patients resided in urban areas (84.4\%) and were black (73.4\%; Table 1). Of the 152,455 intervals analyzed, 575 were acute stroke within 1 year; 2,104 were more than 1 year after acute stroke; 3,980 intervals had CKD; 1,894 had ESRD; and 12,141 had PH. EOD was more prevalent among adults than among patients aged 12-17 years (acute stroke:
$16.8 \%$ for adults vs. $14.1 \%$ for patients aged $12-17$ years; CKD: $6.8 \%$ vs. $1.5 \%$; ESRD: $3.1 \%$ vs. $0.2 \%$; and PH: $17.1 \%$ vs. $5.6 \%$ ).

\section{All-Cause Health Care Utilization}

A higher proportion of patients with EOD than without it had inpatient hospitalizations (44.8\% vs. $19.6 \%$ ), physician office visits ( $78.5 \%$ vs. $69.8 \%$ ), ED visits ( $44.1 \%$ vs. $32.7 \%$ ), laboratory tests $(75.5 \%$ vs. $62.5 \%)$, other outpatient services $(84.4 \%$ vs. $73.0 \%$ ), and outpatient pharmacy claims ( $89.3 \%$ vs. $78.9 \%$ ). Similarly, compared with patients without EOD, patients with EOD had a higher mean number of days of inpatient hospitalization PPPM (1.9 vs. 0.4), physician office visits (1.2 vs. 0.8 ), ED visits (0.6 vs. 0.3), laboratory tests (4.8 vs. 2.5 ), other outpatient services (3.2 vs. 1.4), and outpatient pharmacy claims (4.5 vs. 2.2; Table 2). The average number of ED visits was highest among intervals in which the patient had ESRD with a mean (SD) of 0.9 (2.1) visits PPPM (Table 2).

The mean number of days of inpatient hospitalization was 6 times and nearly 3 times higher among individuals with acute 


\begin{tabular}{l|c|c|c}
\hline TABLE 4) & \multicolumn{3}{l}{$\begin{array}{l}\text { Estimated Mean Annual Costs, Inpatient } \\
\text { Days, and Number of ED Visits per Year } \\
\text { for Adult Medicaid Patients with SCD }\end{array}$} \\
\hline & $\begin{array}{c}\text { Adjusted } \\
\text { Costs } \\
\text { for Adults, } \$\end{array}$ & $\begin{array}{c}\text { Adjusted } \\
\text { Inpatient } \\
\text { Days }\end{array}$ & $\begin{array}{c}\text { ED } \\
\text { Visits }\end{array}$ \\
\hline$\leq 1$ year after acute stroke & 285,816 & 33.90 & 9.23 \\
\hline >1 year after acute stroke & 127,393 & 16.01 & 10.00 \\
\hline CKD & 135,493 & 19.91 & 8.93 \\
\hline ESRD & 209,172 & 29.09 & 12.31 \\
\hline PH & 148,174 & 26.55 & 8.57 \\
\hline
\end{tabular}

$C K D=$ chronic kidney disease; $E D=$ emergency department; $E S R D=$ end-stage renal disease; $\mathrm{PH}=$ pulmonary hypertension; $\mathrm{SCD}=$ sickle cell disease.

stroke within 1 year and more than 1 year, respectively, compared with patients without EOD (mean days hospitalization PPPM 2.5 vs. 1.1 vs. 0.4). In addition, the mean (SD) cost per hospitalization for acute stroke was $\$ 55,314(\$ 76,847)$.

\section{Multivariate Regression Results}

After adjusting for demographic and clinical characteristics, multivariate regression analysis revealed significantly higher costs for patients with EOD, compared with those for patients without EOD (with cost ratios of 4.68 for within 1 year after acute stroke, 2.08 for more than 1 year after stroke, 2.19 for CKD, 3.40 for ESRD, and 2.32 for PH; $P<0.0001$; Table 3). Patients aged 18 to 30 years (the reference group) had the highest costs associated with SCD and EOD (cost ratios for all other age groups were $<1.00 ; \mathrm{P}$ values $<0.0001$; Table 3). Patients with other SCD complications also had significantly higher costs than patients without EOD, with a cost ratio of 2.10 for avascular necrosis $(P<0.0001) ; 2.06$ for gallstones, cholelithiasis, and cholecystitis $(P<0.001) ; 1.60$ for leg ulcers $(P<0.01)$; 1.84 for osteomyelitis $(P<0.0001)$; and 1.65 for priapism $(P<0.0001)$. Adjusted mean annual costs for adult patients on Medicaid with SCD and with stroke were $\$ 285,816$ for strokes that occurred within 1 year and $\$ 127,393$ if more than 1 year after a stroke (Table 4). In patients with CKD, ESRD, or PH, the adjusted costs were $\$ 135,493, \$ 209,172$, and $\$ 148,174$, respectively. Patients with multiple SCD complications had even higher costs, with an adjusted mean annual cost for adult patients with CKD and avascular necrosis of $\$ 270,513$, and $\$ 417,614$ for adult patients with ESRD and avascular necrosis.

Multivariate regression models were also used to estimate the annual number of days in hospital and number of ED visits per patient for adults (Table 3). Consistent with the cost results, most age groups were associated with a decrease in inpatient days and ED visits compared with the reference age group of 18-30 years. The adjusted annual number of inpatient days per patient were 33.90 days for patients with strokes that occurred within 1 year and 16.01 days if more than 1 year after stroke
(Table 4). In patients with CKD, ESRD, or PH, the adjusted annual inpatient days were 19.91, 29.09, and 26.55 days, respectively. The highest annual number of adjusted ED visits per patient was observed among adults with ESRD, compared with those without EOD (mean 12.31 vs. mean 5.50; ratio 2.25; $P<0.01)$

\section{Productivity Loss}

Among the 10,784 Medicaid patients with SCD, the average time spent receiving health care services was 55-62 days per patient per year (PPPY) for those with any EOD versus 21-25 days PPPY for those without EOD (Table 5). Patients with ESRD or acute stroke within 1 year spent the most time on health care services (ESRD: 76-100 days PPPY; within 1 year of acute stroke: 70-95 days PPPY; Table 5).

\section{Discussion}

Although studies have demonstrated the significant economic burden incurred by patients with SCD across their lifespans, 4,5 limited research has been conducted to measure the economic burden of EOD among patients with SCD in the United States. To address this research gap, this study of patients with SCD with Medicaid insurance compared health care utilization, productivity loss, and direct costs among patients with and without EOD (stroke, CKD, ESRD, and PH). This study found that patients with SCD and EOD had more days in hospital, ED visits, outpatient visits, laboratory tests, and outpatient pharmacy claims per month than patients without EOD. Patients with any EOD, especially those with multiple complications, had significantly higher annual costs $(\$ 270,513$ for adult patients with SCD and CKD and avascular necrosis) than those without EOD $(\$ 59,845)$. Furthermore, patients with SCD and EOD spent more than double the amount of productive time on health care than patients with SCD without EOD.

Previous studies of health care utilization among patients with SCD have focused on the location of care and primary purpose for the visit. Among patients with SCD, 50.7\% of all hospitalizations were for patients aged 18-34 years. ${ }^{3}$ However, previous studies primarily considered the SCD population overall without considering the heterogeneity among patients, especially the direct and indirect costs associated with EOD in SCD. SCD is heterogenous in its clinical presentation; thus, the burden of illness varies. In this study, Medicaid patients with SCD and ESRD and within 1 year after acute stroke were found to have the highest rates of inpatient hospitalization and longest length of stay, which provides insight into target opportunities for care coordination among different provider types to address needs of patients with SCD and EOD.

Most studies have examined the costs among patients with SCD by age group and health care service. In a population of Florida Medicaid SCD patients, more than half (51.8\%) of health care costs were attributed directly to SCD-related care, 
The Economic Burden of End-Organ Damage Among Medicaid Patients with Sickle Cell Disease in the United States: A Population-Based Longitudinal Claims Study

\section{TABLE 5 Time Spent Receiving Health Care Estimates Among Medicaid Patients with SCD}

\begin{tabular}{|c|c|c|c|c|c|c|c|}
\hline & $\begin{array}{c}\text { No EOD } \\
(\mathrm{n}=134,444)\end{array}$ & $\begin{array}{c}\text { EOD } \\
(\mathrm{n}=18,011)\end{array}$ & \begin{tabular}{|c|}
$\leq 1$ Year \\
After Acute \\
Stroke \\
$(\mathrm{n}=575)$ \\
\end{tabular} & $\begin{array}{c}>1 \text { Year } \\
\text { After Acute } \\
\text { Stroke } \\
(\mathbf{n}=2,104)\end{array}$ & $\begin{array}{c}\text { CKD } \\
(\mathbf{n}=3,980)\end{array}$ & $\begin{array}{c}\text { ESRD } \\
(\mathrm{n}=1,894)\end{array}$ & $\begin{array}{c}\text { PH } \\
(n=12,141)\end{array}$ \\
\hline \multicolumn{8}{|l|}{ Mean number of hours lost, PPPM } \\
\hline Inpatient hospitalization (8 hours/day) & 3.58 & 14.88 & 19.91 & 8.74 & 13.12 & 20.38 & 16.82 \\
\hline Physician office visits (2 hours/visit) & 1.53 & 2.33 & 2.55 & 2.41 & 2.39 & 2.48 & 2.37 \\
\hline ED visits (6 hours/visit) & 1.54 & 3.74 & 3.08 & 2.86 & 3.35 & 5.35 & 3.77 \\
\hline Lab test visit (2 hours/visit) & 5.00 & 9.61 & 14.03 & 15.90 & 9.03 & 12.37 & 8.70 \\
\hline Lab test visit (1 hour/visit) & 2.50 & 4.81 & 7.02 & 7.95 & 4.52 & 6.19 & 4.35 \\
\hline Other outpatient services (2 hours/visit) & 2.85 & 6.49 & 9.61 & 7.58 & 7.82 & 9.79 & 6.24 \\
\hline Other outpatient services (4 hours/visit) & 5.70 & 12.99 & 19.22 & 15.16 & 15.63 & 19.59 & 12.48 \\
\hline Outpatient pharmacy claims (1 hour/visit) & 2.20 & 4.53 & 4.23 & 4.46 & 5.04 & 6.40 & 4.52 \\
\hline \multicolumn{8}{|l|}{ Total days lost, PPPY } \\
\hline All settings (2 hours/outpatient visit; 2 hours/lab tests) & 25.04 & 62.38 & 80.11 & 62.94 & 61.12 & 85.18 & 63.63 \\
\hline All settings (4 hours/other outpatient visit; 2 hours/lab tests) & N/A & N/A & 94.53 & 74.31 & N/A & 99.87 & N/A \\
\hline All settings (2 hours/outpatient visit; 1 hour/lab tests) & 21.29 & 55.17 & 69.59 & 51.01 & 54.35 & 75.90 & 57.11 \\
\hline
\end{tabular}

with the highest PPPM costs among patients aged 30-39 years. ${ }^{5}$ The lifetime cost of health care for patients with SCD has been well documented. ${ }^{6}$ Another study using the IBM MarketScan Commercial Database from 2005 to 2015 estimated that the incremental economic burden of SCD among individuals was $\$ 2.98$ billion per year in the United States. Of those costs, 57\% were inpatient costs; $38 \%$ were outpatient costs; and 5\% were out-of-pocket expenses. ${ }^{18}$ Whereas these studies advanced understanding of the significant financial burden for children and adults with SCD, our findings delineate cost differences between patients with SCD with and without the complications of acute stroke, CKD, ESRD, and PH. Such findings are nuanced, since previous research primarily focused on either the prevalence and disease trajectory of patients with SCD with particular complications ${ }^{11-14}$ or the costs of stroke, CKD, and ESRD independent of SCD. ${ }^{19-21}$ One study examining claims from the California Patient Discharge Database from 1998 to 2007 did report the length of stay and hospital charges for patients with SCD who were admitted for acute stroke.22 That study reported higher hospital charges among patients with SCD who were treated for acute stroke (hemorrhagic stroke median $\$ 79,307$; ischemic stroke median $\$ 32,216$ ), as compared with hospitalization for other diagnoses among patients with stroke (median $\$ 16,005$ ). Our study found that the average cost per hospitalization for acute stroke was $\$ 55,314$, which was notably higher than the average hospitalization cost for stroke among the general population $(\$ 20,396){ }^{23}$

An additional component of the economic burden experienced by patients with SCD is the lost productivity resulting from the significant time spent receiving services for disease and pain management. In 1 study conducted at the Virginia
Commonwealth University's adult sickle cell clinic, ${ }^{10} 43.8 \%$ of adult patients reported that they were unable to work as a result of SCD disease management and the severity of pain symptoms. In addition, $75 \%$ of patients with SCD reported missing work because of SCD, with an average of 36.75 days missed annually. Although the Medicaid database used in the current study did not enable investigation of short-term disability or work absences, ${ }^{24}$ this study estimated the indirect work loss by quantifying time spent receiving health care as a proxy for "productivity loss." Patients with SCD and EOD were estimated to spend more than double the amount of productive time (55-62 days PPPY) on health care than patients with SCD without EOD (21-25 days PPPY); patients with SCD and ESRD receiving recurrent treatment for dialysis spent a particularly large amount of time on health care (91-100 days PPPY). Future studies should make an effort to collect productivity loss data among patients with SCD to accurately quantify the effect of SCD on society beyond the health care system.

\section{Limitations}

The limitations of this study include those inherent in any retrospective analysis. First, this study was limited to only those individuals with Medicaid. Consequently, results of this analysis may not be generalizable to patients with other insurance (e.g., commercial and Medicare) or patients without health insurance coverage.

Second, the potential for misclassification of SCD, covariates, or study outcomes was present, since patients were identified through administrative claims data as opposed to medical records. As with any claims database, the MarketScan Research Databases rely on administrative claims data for clinical detail. 
These data are subject to data coding limitations and data entry error. Full patient histories were not available, and diagnoses of EOD before the January 1, 2008, index date may have been missed. Although the most prevalent complication was $\mathrm{PH}$, given the young age of the population, $\mathrm{PH}$ was not likely defined through right-catheterization and was likely defined by echocardiography. While patients with SCD could be identified through the validated algorithm, the severity of SCD could not be examined. Although statistical analysis was conducted to adjust for patient characteristics, systemic differences may still exist between patients with and without EOD. Additionally, the longitudinal panel data analysis did not perform standardization of costs and utilization for intervals that were less than 30 days. This conservative estimate minimized inflation of PPPM costs; however, the short duration of panel-data estimates did not equally capture the costs and utilization for patients with incomplete intervals.

Finally, to quantify the time spent receiving health care (or potential productivity loss for patients or their caregivers) based on health care resource utilization, a specified number of hours were assigned for each health care service as a proxy for the number of hours lost, which may have over- or underestimated actual productivity loss. Productivity loss estimates may also differ across specialties or geography, and these differences were not accounted for in this analysis.

\section{Conclusions}

SCD is associated with substantial economic burden. When patients experience EOD such as stroke, renal dysfunction, cardiopulmonary conditions, or other SCD complications, this economic burden is significantly increased. The effect of major EOD in SCD on patient and/or caregiver productivity loss is also substantial. SCD management strategies that can potentially reduce the risks of EOD offer clinical and economic value to patients and society.

\section{Authors}

ANDREW CAMPBELL, MD, Children's National Medical Center, Washington, DC. ZE CONG, PhD, and IRENE AGODOA, MD, Global Blood Therapeutics, South San Francisco, California. XUE SONG, PhD; DIANE J. MARTINEZ, DrPH, MPH; DANAE BLACK; CAROLYN R. LEW, PhD; HELEN VARKER; and CHRIS CHAN, MPH, IBM Watson Health, Cambridge, Massachusetts. SOPHIE LANZKRON, MD, MHS, Johns Hopkins University, Baltimore, Maryland.

AUTHOR CORRESPONDENCE: Ze Cong, PhD, Global Blood Therapeutics, 181 Oyster Point Blvd., South San Francisco, CA 94080.Tel.: 650.351.4789; E-mail: zcong@gbt.com.

\section{DISCLOSURES}

Funding for this study was provided by Global Blood Therapeutics (GBT). Campbell is a consultant for GBT, Bluebird Bio, and Cyclerion and receives research funding from Novartis, GBT, and Cyclerion. Cong and Agodoa are employees of and have equity ownership in GBT. Song, Martinez, Black, Lew, Varker, and Chan are employees of IBM Watson Health, which received research funding from GBT for this study. Lanzkron receives research funding from GBT, Pfizer, Ironwood, HRSA, and NIH.

A poster based on this study was presented at the 6lst ASH Annual Meeting and Exposition; December 7-10, 2019; Orlando, FL.

\section{ACKNOWLEDGMENTS}

Nelson Jen, PhD (Healthcare Consultancy Group, with funding from GBT) provided editorial assistance in the preparation of this report.

\section{REFERENCES}

1. Centers for Disease Control and Prevention. What is sickle cell disease? October 21, 2019. Available at: https://www.cdc.gov/ncbddd/sicklecell/facts. html. Accessed June 4, 2020.

2. National Heart Lung and Blood Institute. Evidence-Based Management of Sickle Cell Disease. Expert Panel Report, 2014. Bethesda, MD: National Institutes of Health; 2014.

3. Fingar K, Owens P, Reid L, Mistry K, Barrett M. Characteristics of inpatient hospital stays involving sickle cell disease, 2000-2016. HCUP Statistical Brief \#251. September 2019. Available at: https://hcup-us.ahrq gov/reports/statbriefs/sb251-Sickle-Cell-Disease-Stays-2016.jsp. Accessed June 4, 2020.

4. Ballas SK, Kanter J, Agodoa I, et al. Opioid utilization patterns in United States individuals with sickle cell disease. Am J Hematol. 2018;93(10): E345-E347.

5. Kauf TL, Coates TD, Huazhi L, Mody-Patel N, Hartzema AG. The cost of health care for children and adults with sickle cell disease. Am J Hematol. 2009;84(6):323-27.

6. Ballas SK. The cost of health care for patients with sickle cell disease Am J Hematol. 2009;84(6):320-22.

7. Ballas SK, Lieff S, Benjamin LJ, et al. Definitions of the phenotypic manifestations of sickle cell disease. Am J Hematol. 2010;85(1):6-13.

8. American Society of Hematology. State of sickle cell disease: 2016 report. Available at: http://www.scdcoalition.org/pdfs/ASH\%20State $\% 20$ of $\% 20$ Sickle\%20Cell\%20Disease\%202016\%20Report.pdf. Accessed June 4, 2020.

9. Gordeuk VR, Castro OL, Machado RF. Pathophysiology and treatment of pulmonary hypertension in sickle cell disease. Blood. 2016;127(7):820-28.

10. Oakes K. Sickle cell disease exacts a heavy vocational toll. 2018. Available at: https://www.mdedge.com/hematology-oncology/article/168531/anemia/ sickle-cell-disease-exacts-heavy-vocational-toll. Accessed June 4, 2020.

11. Bernaudin F, Verlhac S, Arnaud C, et al. Long-term treatment follow-up of children with sickle cell disease monitored with abnormal transcranial Doppler velocities. Blood. 2016;127(14):1814-22

12. Drawz P, Ayyappan S, Nouraie M, et al. Kidney disease among patients with sickle cell disease, hemoglobin SS and SC. Clin J Am Soc Nephrol. 2016;11(2):207-15

13. Alkhunaizi AM, Al-Khatti AA, Al-Mueilo SH, Amir A, Yousif B. Endstage renal disease in patients with sickle cell disease. Saudi J Kidney Dis Transpl. 2017;28(4):751-57.

14. Parent F, Bachir D, Inamo J, et al. A hemodynamic study of pulmonary hypertension in sickle cell disease. N Engl J Med. 2011;365(1):44-53.

15. Snyder AB, Zhou M, Theodore R, Quarmyne M-O, Eckman J, Lane PA. Improving an administrative case definition for longitudinal surveillance of sickle cell disease. Public Health Rep. 2019;134(3):274-81. 
The Economic Burden of End-Organ Damage Among Medicaid Patients with Sickle Cell Disease in the United States: A Population-Based Longitudinal Claims Study

16. Yusuf HR, Atrash HK, Grosse SD, Parker CS, Grant AM. Emergency department visits made by patients with sickle cell disease: a descriptive study, 1999-2007. Am J Prev Med. 2010;38(4):S536-S541.

17. National Kidney Foundation. Dialysis. Available at: https://www.kidney. org/atoz/content/dialysisinfo. Accessed June 4, 2020.

18. Huo J, Xiao H, Garg M, Shah C, Wilkie D, Mainous III A. PSY10 The economic burden of sickle cell disease in the United States [abstract]. Value Health. 2018;21(Suppl 2):S108. Available at: https://www. valueinhealthjournal.com/article/S1098-3015(18)33183-8/fulltext. Accessed June 4, 2020 .

19. Dufour R, Pruett J, Hu N, et al. Healthcare resource utilization and costs for patients with pulmonary arterial hypertension: real-world documentation of functional class. J Med Econ. 2017;20(11):1178-86.
20. Golestaneh L, Alvarez PJ, Reaven NL, et al. All-cause costs increase exponentially with increased chronic kidney disease stage. Am J Manag Care. 2017;23(10 Suppl):S163-S172.

21. Demaerschalk BM, Hwang H-M, Leung G. US cost burden of ischemic stroke: a systematic literature review. Am J Manag Care. 2010;16(7):525-33.

22. Strouse JJ, Jordan LC, Lanzkron S, Casella JF. The excess burden of stroke in hospitalized adults with sickle cell disease. Am J Hematol. 2009;84(9):548-52.

23. Wang G, Zhang Z, Ayala C, Dunet DO, Fang J, George MG. Costs of hospitalization for stroke patients aged 18-64 years in the United States. J Stroke Cerebrovasc Dis. 2014;23(5):861-68.

24. Song X, Quek RG, Gandra SR, Cappell KA, Fowler R, Cong Z.

Productivity loss and indirect costs associated with cardiovascular events and related clinical procedures. BMC Health Serv Res. 2015;15(1):245. 
The Economic Burden of End-Organ Damage Among Medicaid Patients

with Sickle Cell Disease in the United States: A Population-Based Longitudinal Claims Study

\begin{tabular}{|c|c|c|}
\hline Code Type & Code & Description \\
\hline ICD-9 DX & 282.41 & Sickle cell thalassemia without crisis \\
\hline ICD-9 DX & 282.42 & Sickle cell thalassemia with crisis \\
\hline ICD-9 DX & 282.60 & Sickle cell disease, unspecified \\
\hline ICD-9 DX & 282.61 & Hb-SS disease without crisis \\
\hline ICD-9 DX & 282.62 & Hb-SS disease with crisis \\
\hline ICD-9 DX & 282.63 & Sickle cell/Hb-C disease without crisis \\
\hline ICD-9 DX & 282.64 & Sickle cell/Hb-C disease with crisis \\
\hline ICD-9 DX & 282.68 & Other sickle cell disease without crisis \\
\hline ICD-9 DX & 282.69 & Other sickle cell disease with crisis \\
\hline ICD-10 DX & D5700 & Hb-SS disease with crisis, unspecified \\
\hline ICD-10 DX & D5701 & Hb-SS disease with acute chest syndrome \\
\hline ICD-10 DX & D5702 & Hb-SS disease with splenic sequestration \\
\hline ICD-10 DX & D571 & Sickle-cell disease without crisis \\
\hline ICD-10 DX & D5720 & Sickle-cell/Hb-C disease without crisis \\
\hline ICD-10 DX & D57211 & Sickle-cell/Hb-C disease with acute chest syndrome \\
\hline ICD-10 DX & D57212 & Sickle-cell/Hb-C disease with splenic sequestration \\
\hline ICD-10 DX & D57219 & Sickle-cell/Hb-C disease with crisis, unspecified \\
\hline ICD-10 DX & D5740 & Sickle-cell thalassemia without crisis \\
\hline ICD-10 DX & D57411 & Sickle-cell thalassemia with acute chest syndrome \\
\hline ICD-10 DX & D57412 & Sickle-cell thalassemia with splenic sequestration \\
\hline ICD-10 DX & D57419 & Sickle-cell thalassemia with crisis, unspecified \\
\hline ICD-10 DX & D5780 & Other sickle-cell disorders without crisis \\
\hline ICD-10 DX & D57811 & Other sickle-cell disorders with acute chest syndrome \\
\hline ICD-10 DX & D57812 & Other sickle-cell disorders with splenic sequestration \\
\hline ICD-10 DX & D57819 & Other sickle-cell disorders with crisis, unspecified \\
\hline
\end{tabular}

